\title{
“Viver ATÉ O Dia DA SUA MORTE”: UMA Discussão AcERCA DOS Cuidados Paliativos Com Crianças A Partir Do Filme OPERAÇÃo Big Hero
}

\author{
Lurian Ruth Nabozny ${ }^{1}$ \\ Rosanna Rita Silva ${ }^{2}$
}

\section{RESUMO}

Este artigo discorre sobre o funcionamento pulsional nas toxicomanias. A toxicomania é um modo de existir em que a droga se torna central, funcionando como objeto privilegiado da pulsão. Por esse motivo, ela pode ser considerada uma das expressões mais claras da pulsão de morte desfusionada, conquanto não configure uma compulsão à repetição. $O$ toxicômano, prescindindo da relação com os outros, manipula quimicamente as fontes pulsionais com o tóxico, regredindo ao autoerotismo.

PALAVRAS-CHAVE: Toxicomania; Pulsão; Droga; Pulsão de Morte.

\footnotetext{
1 Acadêmica do curso de Psicologia da Universidade Estadual do Centro-Oeste do Paraná (PR). inabozny95@gmail.com.

2 Professora do curso de Psicologia da Universidade Estadual do Centro-Oeste do Paraná (PR). rosanna.irati@unicentro.br
}

179 Psicanálise \& Barroco em revista | v.17, n. 01 | julho de 2019 


\title{
INTRODUÇÃO
}

\author{
Na mesma pedra se encontram, \\ Conforme o povo traduz, \\ Quando se nasce - uma estrela, \\ Quando se morre - uma cruz. \\ Mas quantos que aqui repousam \\ Hão de emendar-nos assim: \\ "Ponham-me a cruz no princípio... \\ E a luz da estrela no fim!". \\ (Mario Quintana)
}

Há sempre uma temática que nos captura e diante disto a pesquisa nos proporciona um encontro com aquilo que, de alguma forma, nos habita. Tal experiência faz com que passemos a abordar um tema de uma nova forma e, movidos por um interesse incomum passamos a investigá-lo por diversos âmbitos da nossa vida.

As vezes em que li Mario Quintana, tive a impressão de que o tema da morte se presentifica em algumas das suas escritas. Apesar de já ter lido alguns dos seus poemas, talvez essa característica só tenha sido realmente tocante quando comecei a estudar a morte.

Os poemas e os filmes, assim como toda forma de arte, nos possibilitam uma aproximação com nossa subjetividade. Buscamos uma interpretação, (se é que podemos interpretar a arte) segundo as nossas vivências, nossos estudos e nossas concepções; logo, são abordagens interessantes para a compreensão de vários assuntos. O filme foi a ferramenta escolhida para auxiliar a escrita e as conclusões que entrelaçam este artigo, que trata dos Cuidados Paliativos (doravante CP) e a discussão sobre o tema da morte a partir da Psicanálise. Um filme pode suscitar diversas reflexões: sobre a vida ou a morte, e auxiliar o paciente a compreender, a seu modo, o processo pelo qual está passando. Dessa forma, nasce a proposta da análise fílmica para criar uma articulação com CP.

O filme escolhido para a análise leva o nome de Operação Big Hero (com título original Big Hero 6), e sua escolha está ligada à faixa etária que concerne a esta pesquisa: as crianças. É um filme do gênero animação/aventura, produzido nos Estados Unidos e lançado no dia 25 de dezembro de 2014. A história diz respeito à vida de Hiro Hamada, um menino de treze anos, que possui grande interesse em 
tecnologia e grande habilidade para a construção de objetos que a envolvam. Hiro é colocado frente à temática de morte desde os três anos, quando seus pais morrem e, com a idade atual, perde o irmão em um incêndio na escola de robótica na qual ele estudava. Antes de morrer, Tadashi Hamada, irmão de Hiro, apresenta a ele o robô Baymax, de sua criação, que inicialmente possui o intuito de melhorar a saúde das pessoas, tanto a emocional, quanto a física. O robô apresentado pelo irmão de Hiro será um dos grandes enfoques do estudo, pois podemos entendê-lo e vê-lo como um profissional que atende em CP, preocupando-se com a saúde mental e física da pessoa que depende dessa forma de atendimento, bem como as questões de morte e luto que aparecem no enredo e envolvem os personagens.

Acreditamos, então, que o filme pode ser um disparador para entender como a questão da morte nos envolve e nos afeta, e como pode interferir na vida da criança, podendo gerar grave adoecimento. A partir disso, é possível também, compreender como se dá a aplicação dos cuidados paliativos, como trabalhar as questões relacionadas à morte e ao luto com as crianças e como se dá a atuação dentro dessa área de alcance da Psicologia. Para isso foram selecionadas três cenas do filme mencionado e, a partir delas, serão trabalhadas questões que envolvem o tratamento em CP.

Podemos pensar que a morte é uma temática que cerca a vida das pessoas diariamente, mas em contrapartida, comparece também uma evitação no enfrentamento da mesma. Isso nos coloca o questionamento: se a morte é a única certeza presente nas nossas vidas, porque, é um tema tão permeado por tabus?

Segundo Freud, a morte é inevitável, inquestionável e natural. Em "Escritos sobre a Guerra e a Morte", sublinha: "[...] no fundo, ninguém acredita na sua própria morte ou, o que é a mesma coisa, no inconsciente, cada qual está convencido da sua imortalidade" (FREUD, 1914-1916, p. 19). Freud pontua que os sujeitos procuram afastar-se da ideia de sua própria morte, mas ficam à mercê quando vivenciam perdas que exigem o trabalho do luto, tais como o final de um relacionamento, ou a perda de um ente querido. Precisamos, assim, entendê-la, para melhor compreender a forma como ela nos afeta, tal como exposto anteriormente.

Existem sujeitos que são colocados frente à finitude quando descobrem que estão com uma doença grave, a qual já não apresenta mais possibilidade de cura. Nesse sentido, uma equipe multiprofissional se dedica ao estudo e aprimoramento de 
"Viver até O Dia Da Sua Morte": Uma Discussão Acerca Dos Cuidados Paliativos Com Crianças A Partir Do Filme Operação Big Hero

técnicas que viabilizem o entendimento do contexto desses pacientes. Essa equipe leva o nome de cuidadores paliativos.

Menezes (2004), citada por Silva e Sudigursky (2008), indica que o cuidado paliativo atinge o paciente que está fora das possibilidades de cura, não somente na fase terminal, mas durante todo o percurso que a doença pode desenvolver. Sobre o paciente destaca:

[...] apresenta fragilidades e limitações bastante específicas de natureza física, psicológica, social e espiritual. Trata-se daquele paciente, para o qual a ciência não possui recurso para deter o avanço fatal da doença, trazendo interrogações para a equipe de saúde, familiares e para o próprio indivíduo. (SILVA e SUDIGURSKY 2008, p.505).

Segundo Gomes (2016), quando se trata de CP, o cuidado que é disponibilizado ao paciente não terá um viés de cura, uma vez que evitar a morte já não é mais uma possibilidade. Assim, o cuidador paliativo atua como facilitador para a compreensão do sujeito quanto a sua atual situação, procurando confortar as angústias que possam surgir. Essa atuação busca alcançar também os familiares e amigos do paciente para amenizar as dores emocionais e físicas, sempre priorizando o respeito pelo tempo de aceitação da finalidade da vida.

Nesse sentido, o CP apresenta a proposta do olhar direcionado ao paciente que não responde mais às intervenções curativas ofertadas, como meio de controle dos sintomas da doença e sofrimento, mas oferta uma maior qualidade de vida aos pacientes. Sabe-se que os sujeitos com doenças terminais frequentemente sofrem com dores físicas, entretanto, os conflitos psicológicos instaurados pela condição na qual o paciente se encontra também precisam ser trabalhados, o que nos clarifica o papel do psicólogo nesse tipo de atendimento.

Podemos pensar, então, na qualidade de vida desses sujeitos, que se liga com a significação que pode ser suscitada em suas vidas, bem como no seu entendimento do processo do adoecimento, aceitação e organização de possíveis conflitos. "O principal negócio da pessoa cronicamente doente não é somente estar vivo ou manter seus sintomas sob controle, mas viver o mais normalmente possível a despeito dos sintomas e da doença [...]" (STRAUSS et al. apud CASTELLANOS, 2011, p.39).

Nesse tempo de aceitação, a questão do luto deverá ser trabalhada com as pessoas envoltas pelo processo de aceitação da morte. Assim, podemos nos perguntar: 
Em que consiste o trabalho realizado pelo luto? [...] O exame da realidade mostrou que o objeto amado não mais existe, e então exige que toda libido seja retirada de suas conexões com esse objeto. Isso desperta uma compreensível oposição - observa-se geralmente que o ser humano não gosta de abandonar uma posição libidinal, mesmo quando um substituto já se anuncia (FREUD, 1915 [1917], p. 173-174).

Trazemos esse fragmento de "Luto e Melancolia", para introduzir a discussão da dificuldade das pessoas em compreender esse processo que os CP se propõem a construir, que coloca os familiares do paciente frente à realocação da sua libido a partir do momento que precisam assimilar que logo perderão um membro que lhes é muito próximo. Também podemos pensar na abordagem do luto e da morte com crianças que, enquanto sujeitos, são tomados como seres incapazes de entender esses temas de forma concreta, tendo em vista que ainda se encontram em formação. Kovács (2016), coloca que o uso de metáforas e eufemismos para trabalhar a morte com crianças pode deixá-las mais confusas e prejudicar a sua recuperação perante o luto, podendo aumentar a dor e criar sentimentos de desamparo.

Sabendo da dificuldade que os sujeitos apresentam quando se trata do enfrentamento e discussão sobre a morte, colocamo-nos o desafio de visualizar essa temática na vida das crianças, especificamente as que precisam encará-la todos os dias. Os CP com crianças envolvem justamente essa explicação sobre a sua condição e o modo como isso será feito, mas, para além disso, existe uma especificidade do trabalho com essa faixa etária, e ela está no envolvimento que ele terá com a família do paciente. Segundo Castellanos (2011), é necessário ter em mente que os familiares desse paciente estarão envoltos o tempo todo com o processo e, por isso, muitas vezes trabalharão complementarmente à ação dos $\mathrm{CP}$. Também é necessário compreender quais as concepções dessa família sobre assuntos como morte, luto e adoecer, por exemplo, para que a partir disso possam ser pensados os próximos passos do cuidado. Pesquisar esses detalhes sobre o decorrer da atuação em CP e como eles acontecem, nos propicia uma possível discussão sobre o tema, o que corrobora na construção de possíveis intervenções nessa área e o aumento do conhecimento sobre os CP. A utilização do filme, o qual é um produto cultural com uma interpretação da temática da morte, viabiliza enxergá-lo a partir de uma perspectiva teórica, o que valoriza esses produtos e o quanto eles podem ser utilizados para debater inúmeras questões da vida dos sujeitos. No que tange essa pesquisa, também é possível justamente pensar sobre esse desdobramento para a 
"Viver até O Dia Da Sua Morte": Uma Discussão Acerca Dos Cuidados Paliativos Com Crianças A Partir Do Filme Operação Big Hero

infância, que ainda é pouco estudado pela academia e por trazer um grau de dificuldade considerável para os profissionais que atuam nessa área.

Para entender como o filme pode ser utilizado como veículo de compreensão de CP e possível ferramenta a ser utilizada para falar sobre a situação na qual a criança com doença terminal está inserida, é necessário primeiro compreender mais detalhadamente o que são os CP e qual a sua importância na vida do paciente. Por isso, o próximo tópico trará maiores definições do que é cuidado paliativo e uma discussão sobre a sua importância na vida de alguém que precisou se haver com a questão da sua própria morte.

Mas, vale antes disso, destacar uma reflexão: quantas vezes passamos os dias vivendo a eternidade que nos acalenta, e deixamos de pensar no quão finito podem ser os risos, as viagens, as brincadeiras e as conversas? Automaticamente vivemos no mundo corrido, e nos enlaces que produzem nós na corda comprida que é a vida, e deixamos de pensar no instante inesperado e sensível que se rompe. A vida nos parece bela, e a morte nos surge como um pequeno espinho que incomoda: difícil de ver, mas sabemos que está presente. E se, por um breve momento, pudéssemos saber quando é chegada a hora do fim, faríamos de nós composições diferentes? E se, às vezes, lembrássemos que a nossa existência nos faz breves porque breve é o instante que nos faz partir?

\section{Cuidados Paliativos: O Olhar Da Vida Acerca Da Morte}

A morte é uma certeza que carregamos escondida dentro de cada um. Ela está nos sorrisos que nos surgem em bons momentos, e também nas cenas que julgamos veementemente que ficarão marcadas durante todas as décadas, décadas estas que ainda contabilizamos que nos acompanharão. O paradoxo do nosso pensamento e de olhar o calendário acreditando, com firmeza, que ainda vamos chegar até aquela data especial marcada de cor diferente no quadrado da folha, é que a morte pode acontecer em qualquer um dos dias da semana, naqueles mais triviais em que acordamos sem grandes expectativas, ou de um jeito banal que antes não conseguíamos vislumbrar.

O convívio com a iminência da morte e a defrontação com a finitude do ser, do estar e do pertencer nos assusta, e nos coloca em um jogo de esconde-esconde com a nossa realidade e com a realidade das pessoas que nos cercam, com as quais partilhamos afeto e boas experiências. Por isso discutir a morte é discutir a vida e o que somos capazes de produzir, sentir e esperar no nosso cotidiano, seja fazendo 
pequenos planos diários ou programações a longo prazo. E também é possível discutir vida mesmo com aqueles sujeitos, que enfrentam a sua finitude.

Tendo isso em mente, receber a notícia de que se está com uma doença como o câncer, por exemplo, pode nos remeter à falta de cura e desesperança quanto ao tratamento, o que abre a possibilidade de redirecionarmos alguns medos existentes que nos desesperam e paralisam. São notícias que nos posicionam no enfrentamento a essa temática da morte que estamos energicamente dispostos a negar, e que colocam em jogo nossas convicções: o que julgamos ter construído e cimentado em bases fortes, acaba sendo derrubado na tempestade da notícia, é um "profundo arranhão no desejo de ver garantida a fantasia onipotente de segurança e imortalidade" (LABAKI, 2012, p. 19).

Nesse sentido, alguns profissionais colocaram-se dispostos a estudar esses desdobramentos da vida, e, principalmente auxiliar pacientes e seus familiares que se tornam conscientes quanto à finitude de ser somente quando se deparam com um possível impedimento de continuar o rumo normal e corriqueiro que seguiam antes de entender que agora estão com uma doença crônica, degenerativa ou terminal, ou que estão envoltos por essa realidade que os impossibilita de continuar suas atividades como previamente faziam.

Esses profissionais que se dispõem a acompanhar os pacientes e seus familiares em estágios avançados ou terminais, com doenças crônicas ou progressivas, e direcionam a sua formação e carreira com o intuito de aprimorar as técnicas que incluem essa prática, estão na equipe de CP. "A equipe profissional em cuidados paliativos assume a conduta de não eliminar a morte da vida, encarando-a de frente, não recuando desse encontro, falando sobre a vida, os fantasmas da morte e a vida que há na morte" (LIMA, 2014, s/p.).

A Organização Mundial da Saúde (OMS), citada pelo Manual de Cuidados Paliativos, informa:

Cuidado Paliativo é uma abordagem que promove a qualidade de vida de pacientes e seus familiares, que enfrentam doenças que ameacem a continuidade da vida, através da prevenção e alívio do sofrimento. Requer a identificação precoce, avaliação e tratamento da dor e outros problemas de natureza física, psicossocial e espiritual (OMS, 2012, p. 26),

Cuidar de pacientes, que já não correspondem mais aos tratamentos curativos ofertados, lança um desafio a uma equipe multidisciplinar de controle de dor e outros sintomas, que, além de físicos, também estão inclusos na ordem psicológica, social e

185 Psicanálise \& Barroco em revista | v.17, n. 01 | julho de 2019 
"Viver até O Dia Da Sua Morte": Uma Discussão Acerca Dos Cuidados Paliativos Com Crianças A Partir Do Filme Operação Big Hero

espiritual, por exemplo, como discorrem Ferreira, Lopes e Melo (2011) e também conforme citado acima pela OMS. Também os desafia no que tange o envolvimento no âmbito familiar do paciente e coloca esses profissionais num enfrentamento recorrente com a morte e a finitude a que estamos predispostos.

Como dito, a equipe de CP é multidisciplinar, ou seja, é composta por profissionais de diversas áreas;

[...] cada profissional é chamado a desempenhar sua profissão em um processo de trabalho coletivo, cujo produto deve ser fruto de um trabalho formado pela contribuição das diversas áreas profissionais, esperando-se que os integrantes das equipes sejam capazes não só de conhecer e analisar o trabalho, mas também de compartilhar conhecimentos e informações. (FERREIRA, VARGA \& SILVA, 2009. 1422, s/p).

Quando se trata de CP, a equipe é formada por médicos, enfermeiros, assistentes sociais, psicólogos e outros profissionais de áreas distintas (INCA, s/d) que podem completar a mesma, conforme a necessidade do paciente e de sua família, acompanhando e respeitando as suas crenças e convicções, sempre compartilhando do objetivo de minimizar o sofrimento. Apresentamos como exemplo os conselheiros espirituais, que estão ligados com a esfera espiritual de cuidados e se fazem necessários em algumas situações por compartilharem das crenças que sustentam o sujeito e seus familiares.

A atuação da equipe de CP passa a ser requerida durante as últimas semanas ou últimos seis meses de vida do paciente, a partir do momento em que o diagnóstico é capaz de mostrar o declínio progressivo do estado em que o sujeito se encontra. Segundo Santos (2011), os CP asseguram que o alívio do sofrimento possa ser buscado, mesmo que a doença se apresente de maneira incisiva e que traga sobrecarga. A partir disso, existe o zelo pela autonomia, autocuidado e que se aumente a aproximação com os entes queridos, conforme o INCA (s/d) demonstra.

Esse tipo de cuidado foi estabelecido segundo alguns princípios que possibilitam melhor alcance aos sujeitos que precisam do atendimento da equipe. Segundo o Manual de Cuidados Paliativos (2012, p. 26-27), são nove esses princípios e estão ligados com a promoção do alívio da dor e de outros sintomas desagradáveis; afirmar a vida e considerar a morte como um processo natural da mesma; não acelerar e nem adiar a morte do paciente; visualizar os aspectos psicológicos e espirituais integralmente no cuidado com o sujeito; oferecer suporte ao paciente com vias de possibilitá-lo viver o mais ativamente possível até o momento da sua morte; oferecer 
auxílio aos familiares durante a doença do paciente e a enfrentar o luto; oferecer abordagem multiprofissional para atender as necessidades dos pacientes e seus familiares, incluindo acompanhamento no luto; melhorar a qualidade de vida e influenciar positivamente o curso da doença; e por fim, deve ser iniciado o mais precocemente possível, juntamente com outras medidas de prolongamento da vida, como a quimioterapia e a radioterapia e incluir todas as investigações necessárias para melhor compreender e controlar situações clínicas estressantes.

No caso dos CP com crianças, como explana Castellanos (2011), a condição de doença crônica, degenerativa e progressiva se torna mais complexa por envolver os planos e expectativas que nelas são depositados. A criança é colocada em um critério de sujeito em desenvolvimento, em transformação constante e dono de um conjunto de possibilidades futuras, que muitas vezes se entrelaçam com a trajetória de vida dos seus pais, responsáveis e familiares Neste sentido aponta Castellanos: "A criança, mais do que o adulto, é vista como um ser intermediado por contextos físicos, psicológicos e sociais, sujeita que está a esses contextos" (CASTELLANOS, 2011, p. 51).

Pensando nisso, é possível entender que o diagnóstico da doença na criança está sempre envolto pelos projetos dos que fazem parte do seu círculo de convivência. Desta forma, segundo o mesmo autor, os pais e todos os envolvidos na vida da criança são constantemente orientados a questionamentos sobre os sentidos do adoecer e do cuidado. A busca atrelada a esses sentidos tem a ver como os sujeitos identificam algumas situações e se posicionam perante as mesmas. Por isso, o maior desafio é compreender como a criança está sendo vista e tratada pelas pessoas que estão em seu convívio para, a partir disso, conseguir estabelecer o melhor modo de intervir na vida da criança e desses sujeitos.

Os cuidadores das crianças, leigos (familiares) ou especializados
(profissionais), irão agir complementarmente para garantir o seu bem-estar.
Porém, tais cuidadores também disputam a todo o momento os sentidos
sobre as suas ações, assumindo diferentes posições ao longo do processo
de adoecimento infantil (sendo por ele afetados também de maneira
dinâmica) (CASTELLANOS, 2011, p. 53).

Os CP com crianças são realizados sempre em consonância com o entendimento do funcionamento do seu meio, ou seja, a família dessa criança tem papel fundamental nesse processo, sendo que o atendimento também se estende aos seus membros, seja no intuito de capacitá-los ao atendimento do sujeito que retorna 
"Viver até O Dia Da Sua Morte": Uma Discussão Acerca Dos Cuidados Paliativos Com Crianças A Partir Do Filme Operação Big Hero

a sua casa para receber tratamento, quanto à ajuda psicológica devido ao envolvimento com a situação de terminalidade da vida. Entendemos, então, que a convivência por parte destes e outros participantes da vida do sujeito também se abre como território de intervenção da equipe multiprofissional, pois isso resultará no aumento da qualidade dos cuidados oferecidos aos pacientes.

Agora que apresentamos brevemente o que são os $\mathrm{CP}$, quais os objetivos desse tratamento e quais pessoas passam por esse processo, podemos aprofundar nas questões teóricas que nos levam a refletir sobre como os CP acontecem na vida das crianças. Este aprofundamento estará presente na análise das três cenas do filme Operação Big Hero escolhidas, próximo tópico desta pesquisa.

\section{TrAJetóRIA Metodológica}

Uma forma de desencadear uma reflexão sobre o novo andamento da vida de uma criança em Cuidados Paliativos é a utilização da linguagem fílmica, caminho que tomamos aqui.

As cenas de um filme, bem como a construção delas, podem suscitar nas pessoas sentimentos diferentes ligados à temática que elas apresentam. A escolha do filme Operação Big Hero está atrelada a esse intuito de pensar como o desdobramento da história dos personagens pode se aplicar à vida de quem o assiste. Também foi escolhido pela possibilidade de pensar a morte a partir do seu enredo e por ser do gênero animação permite uma aproximação maior ao universo infantil.

A partir do filme, defendemos aqui uma discussão que envolve a criança que está em CP. Para isso foram destacadas e analisadas três cenas do filme Operação Big Hero. Sendo que a primeira cena selecionada apresenta o início do tratamento em CP. A segunda conduz para a reflexão acerca de como a criança lida com a morte e com o luto e, por fim, uma terceira onde se discute a descoberta da doença e a questão da verdade sobre o tratamento e suas implicações.

A história do filme gira em torno de Hiro Hamada e o robô Baymax. Hiro é um menino que sempre esteve ligado à tecnologia e construção de aparatos tecnológicos, influenciado pelo seu irmão Tadashi Hamada, cientista em formação. Baymax é um robô inflável, totalmente branco, criado por Tadashi para prestar assistência às pessoas no que tange a sua saúde, seja ela física ou emocional. Ele foi programado com a classificação de inúmeras doenças que podem nos acometer e também como podemos tratá-las, dessa forma ele é capaz de identificá-las quando disposto frente a 
frente à pessoa que precisa de assistência, e só é desativado quando ela diz que está se sentindo melhor.

Baymax é apresentado a Hiro pelo seu irmão como a sua maior criação até o momento, e o menino fica encantado com o que Tadashi conseguiu construir. Após esse contato entre os dois personagens, o irmão mais velho sofre um acidente na escola de robótica em que estudava e não sobrevive ao incêndio, fato que desperta profunda tristeza em Hiro. Durante determinado momento do filme, Hiro descobre que o incêndio foi criminoso e que um vilão está na cidade, por isso se junta aos amigos de Tadashi e também ao Baymax para derrotá-lo e salvar San Fransokyo, cidade na qual a história é ambientada. Na sequência, passaremos à análise de cada uma das cenas selecionadas, segundo os tópicos escolhidos.

\section{Resultados E Discussão}

\section{Cena 01 - Falando Sobre 0 Início Do Tartamento Em Cuidados Paliativos}

Esta cena mostra a primeira aparição de Baymax na história, sendo que é nela em que ele é apresentado ao Hiro pelo seu irmão Tadashi. O robô é ativado após Hiro ter sido machucado por uma fita adesiva proferindo a interjeição "Ai!", sendo que ele aparece na cena com o propósito de cuidar da enfermidade que está trazendo dor ao garoto. A primeira frase pronunciada pelo robô é "Olá, eu sou o Baymax, seu agente pessoal de saúde. Eu fui programado para te dar atendimento quando disser 'ai'". Na sequência pergunta “Em uma escala de 1 a 10, qual é o nível da sua dor?”. Após Hiro ter perguntado se a dor à qual ele se referia era física ou emocional, o robô o escaneia e enxerga nele o machucado do antebraço, que inicialmente havia sido feito pelo seu irmão. Depois disso, descobre qual remédio deve ser utilizado naquele ferimento e logo em seguida o aplica.

Após tratar o machucado presente no braço do menino, Baymax fala "Não serei desativado até me dizer que está se sentindo melhor", pois a sua programação só permite que ele desinfle quando, finalmente, a pessoa se sente mais confortável com a sua dor e diz que está tudo bem. Hiro, então, diz que está se sentindo melhor, possibilitando que Baymax volte para a sua caixa e seja desativado.

A partir da análise desta cena, alguns detalhes podem ser percebidos na sua construção que nos fazem relembrar o ambiente de atuação dos profissionais de CP. O primeiro ponto a ser visto é a cor de Baymax, personagem que se apresenta

189 Psicanálise \& Barroco em revista | v.17, n. 01 | julho de 2019 
"Viver até O Dia Da Sua Morte": Uma Discussão Acerca Dos Cuidados Paliativos Com Crianças A Partir Do Filme Operação Big Hero

inteiramente de branco como os profissionais que estão inseridos na área da saúde. Entendendo, então, que Baymax poderia ser um cuidador paliativo, qual é a sua função e como acontece esse tratamento?

Segundo INCA (2002), os cuidadores paliativos estão organizados em graus de complexidade que resultam em um cuidado integral e ativo para o paciente, são os cuidados paliativos gerais e específicos. Os CP gerais referem-se ao atendimento ao sujeito que descobre a sua doença e agora percebe seu agravo diariamente. $O$ profissional precisa, então, trabalhar com todo e qualquer sintoma que, eventualmente, apareça na vida do paciente, explicando sobre os seus desdobramentos e também entendendo como o sujeito está sendo capaz de trabalhar essas questões em sua vida. Os CP específicos são requisitados nas últimas semanas ou últimos seis meses de vida, no momento em que se confirma a gravidade da doença e há declínio da condição do sujeito.

\begin{abstract}
Os cuidados ao fim de vida referem-se, em geral, aos últimos dias ou últimas 72 horas de vida. O reconhecimento desta fase pode ser difícil, mas é extremamente necessário para o planejamento do cuidado e preparo do paciente e sua família para perdas e óbito. Mesmo após o óbito do paciente, a equipe de cuidados paliativos deve dar atenção ao processo de morte: como ocorreu, qual o grau de conforto e que impactos trouxe aos familiares e à própria equipe interdisciplinar. A assistência familiar pós-morte pode e deve ser iniciada com intervenções preventivas (INCA, 2002, s/p).
\end{abstract}

Outro elemento que nos chama a atenção no enredo do filme é a escolha da palavra "desativado" para sinalizar o cumprimento da função de Baymax em certos momentos da vida de Hiro. Pressupomos que existe uma "ativação" e "desativação" dos cuidados com o paciente. Relacionamos aqui o papel do psicólogo nesse momento, como se dá a sua inserção e no que ela pode ajudar o sujeito com doença grave.

A atuação do psicólogo tem como alcance justamente essa sinalização da saúde do sujeito: quando ele está precisando de auxílio, o profissional da psicologia é convocado a cumprir o seu papel dentro da equipe multidisciplinar de $\mathrm{CP}$, buscando o alívio e controle dos sintomas presentes na vida do paciente. Aguarda, a partir disso, que o paciente trabalhe as questões da sua vida e busque ficar melhor, o que sinaliza ao psicólogo o cumprimento do seu papel. Dessa forma podemos pensar que existe uma ativação das suas funções e uma desativação quando não são mais necessárias. Qual seria exatamente o papel do psicólogo? 
Juntamente com o conjunto da equipe multiprofissional na qual está inserido, o psicólogo está voltado para a aproximação dos medos, angústias e outros sofrimentos do paciente e da sua família, no sentido de dar assistência e abraçar as queixas presentes, visando qualidade de vida, enquanto vida ainda houver, como Ferreira, Lopes e Melo (2011) expõem, utilizando-se das palavras de Oliveira e Silva. Fala-se em qualidade de vida no intuito de ressaltar que o processo de adoecer pode ser compreendido pelos sujeitos que estão envoltos na situação, seja a família ou o paciente, da melhor maneira possível e ainda mantendo-os ativos nesse processo.

Nunes no Manual de Cuidados Paliativos, cita que, primeiramente, faz-se necessário que o psicólogo atuante na equipe tenha clareza sobre a abordagem a partir da qual atua, tendo conhecimento dos alcances e limitações da mesma, "pois é no avanço articulado entre teoria e prática que vai se definindo a prática e a identidade do psicólogo da equipe" (NUNES, 2012, p. 337). A autora também expõe:

Uma formação básica em Cuidados Paliativos, que permita ao psicólogo conhecer os princípios e temas relevantes para a área, amplia o seu campo de compreensão acerca do contexto em que seu trabalho se insere e contribui para uma atuação sintônica com os objetivos da equipe (NUNES, 2012, p. 337).

É necessário que o psicólogo saiba comunicar-se com a equipe da qual faz parte, sabendo que todos os profissionais trabalharão com o paciente, de alguma forma, visando o melhor atendimento possível, sendo que o "objetivo comum é o de garantir que necessidades distintas do doente, da família e da equipe possam ser reconhecidas e atendidas pela articulação de ações de diferentes naturezas" (NUNES, 2012, p. 337).

A autora também discorre sobre o psicólogo que atua a partir da teoria psicanalítica, área que contribui com a ideia de que

[...] a doença e todo o contexto que a envolve é interpretada pelo doente à
luz de seu discurso, isto é, de seu sistema de afetos e crenças (conscientes
e inconscientes). Considerando isso, o psicanalista oferece a sua escuta
clínica aos que desejam falar, buscando por esse meio favorecer a
elaboração das vivências associadas ao adoecimento. Do ponto de vista do
paciente, isso pode contribuir para a reorganização de uma autoimagem
vilipendiada pela doença e pelo tratamento (NUNES, 2012, p. 338).

Como ressalta Lima (2014), a psicanálise procura respeitar a singularidade dos sujeitos, bem como o direcionamento de como ele resolve passar por esse momento e a maneira como constrói as suas relações. Isso permite que, durante essa ocasião de escuta da angústia presente, nasça uma possibilidade para que o paciente conte 
"Viver até O Dia Da Sua Morte": Uma Discussão Acerca Dos Cuidados Paliativos Com Crianças A Partir Do Filme Operação Big Hero

sobre a sua história e como ela o constituiu, promovendo uma possível abertura para que o mesmo reconstrua a sua vida e fortifique as suas verdades.

[...] Cabe ao psicoterapeuta poder esperar e, passada a tempestade ou quietude, abrir-se com seu paciente para o tempo de investir representações emergentes, possibilitando, então, o início propriamente dito da visada psicoterápica em regime de trocas e movimentos pulsionais (LABAKI, 2012, p. 71).

O psicólogo também tem como pretensão comunicar a família e acompanhá-la no processo de luto e prestação de auxílio ao paciente em CP. Faz isso buscando não amedrontar os familiares, levando em consideração os medos da família, estimulandoos a pensar e falar livremente sobre a situação e sobre seus sentimentos, possibilitando suas elaborações.

Quanto ao que foi citado acima, podemos pensar na "ativação" do papel do psicólogo dentro da equipe de CP, mas e a desativação? A atuação da psicologia se estende para além do óbito do membro que estava recebendo cuidados, pois se entende que o período de luto e ressignificação da perda também são de alcance do trabalho do psicólogo. Dessa forma, a "desativação" do seu exercício se dá apenas

Quando as pessoas com vínculos afetivos fortemente estabelecidos conseguem lidar com as múltiplas mudanças e perdas relacionadas à morte, fazendo uma transição saudável através do processo de luto, [com isso sendo possível] reconstruir suas vidas e se reintegrar à sociedade (GOMES, 2016, p.5).

A "ativação" da Psicologia se dá da maneira mais precoce possível, atendendo qualquer demanda advinda do processo de descobrimento da doença, sua progressão e embates em relação à situação vivenciada. A "desativação" será plenamente possível quando os envolvidos se sentirem capazes de reconstruir as suas vidas e ressignificar o que aconteceu.

Passamos agora à próxima cena e tema alvo da discussão desta pesquisa.

\section{Cena 02 - Falando Sobre A Criança E A Morte}

A cena escolhida para suscitar algumas questões sobre criança e a morte é a em que Tadashi morre no incêndio da escola de robótica. Hiro estava andando com o seu irmão próximo à escola de robótica quando os dois percebem que algo está em chamas. Quando se aproximam para ver, constatam que é a própria escola que está pegando fogo, o que coloca os dois irmãos em grande apreensão. Tadashi escuta que o seu professor permanece dentro da escola e, sem se preocupar com o que 
aconteceria consigo, corre para salvá-lo. O impacto desta cena está na morte de Tadashi, enquanto Hiro o espera fora da escola.

Hiro estava com o irmão durante a sua morte, e precisou entendê-la e presenciá-la mais uma vez. Falamos "mais uma vez" porque a história do filme nos diz que ele já havia perdido seus pais quando mais jovem. Os detalhes que podem ser observados na cena após a morte estão todos voltados para a sensibilização; um memorial é montado para o professor e para Tadashi, o funeral aparece no filme em um dia chuvoso, com música melancólica e as cores do filme permanecem escuras. Detalhes que podem ser ligados a como acontece o luto na vida das pessoas, onde tudo, metaforicamente falando, perde a cor, os sentidos e fica mais lento. Depois do funeral de Tadashi, o filme mostra a grande comoção da família e principalmente a tristeza vivida por Hiro diante da morte do irmão.

Primeiramente trazemos uma reflexão sobre a escolha do título da análise desta cena, utilizando-se da letra "a" antes da palavra "criança" e antes da palavra "morte". Isso foi levado em consideração partindo das ideias adotadas pela abordagem da psicanálise, a qual se volta para o entendimento de que cada sujeito passará pelo processo de morte e vivência do luto de maneira única.

Pensando assim, foi possível elencar a discussão de como enxergamos a criança e os seus entendimentos sobre assuntos como a sua morte e o luto e as especificidades atreladas ao tratamento com crianças e adultos. Vivemos a infância sendo barrados de compreender o que realmente acontece à nossa volta, como se não fôssemos capazes de compreender essas situações por sermos pequenos. Sempre pequenos demais, demasiado frágeis e sensíveis, ou muito suscetíveis à incompreensão ou confusão. A verdade é que nas crianças podemos nos ver, podemos sentirmo-nos inseguros novamente, podemos recriar nossos medos e encarar o passado que lançamos para o inconsciente com o medo veemente de que o conteúdo guardado volte e nos faça perder o controle.

O mundo infantil é gerenciado por novas descobertas e pela liberdade de se construir lentamente o que será no futuro, daí surge a compreensão de que existe a necessidade de ser claro com a criança, sobretudo com o que ela vivência e lhe provoca dúvidas, como propõe Kovács (2016). Dentre essas vivências da criança estão a morte e o luto.

Nosso entendimento de morte é sempre atravessado pela ideia de quantidade de anos vividos, ou seja, a pessoa que está ficando mais velha é aquela que se

193 Psicanálise \& Barroco em revista | v.17, n. 01 | julho de 2019 
"Viver até O Dia Da Sua Morte": Uma Discussão Acerca Dos Cuidados Paliativos Com Crianças A Partir Do Filme Operação Big Hero

aproxima da morte, e os mais jovens ainda serão "honrados" com muitos anos de vida. Entender a finitude da vida dessa forma fortalece a nossa dificuldade em encarar a morte como acontecimento inesperado que pode nos acometer a qualquer momento, em qualquer fase da vida. A negação dessa temática na infância também nos faz ficar surpresos e abalados quando precisamos enfrentar uma situação de morte nessas condições.

"A vovó foi para o céu e virou estrelinha, meu cachorro brincará muito com os outros cachorros do céu, mas para onde foi o meu amigo, e para onde os meus pais vão... E eu, também vou embora? Para onde vou?". O quanto nós conseguimos responder aos questionamentos sobre a morte trazidos pelas crianças, e o quanto isso se liga com a nossa dificuldade em enfrentar a nossa mortalidade? "Vida e morte estão atreladas do início ao fim. Morremos porque vivemos. Esta é a única lei que não se burla e a única certeza que não se contesta" (GRINFIELD, 2016, s/p.).

Não é incomum pensarmos que a criança não tem um psiquismo completamente formado, que talvez não conseguisse entender assuntos que para nós também se tornam difíceis, e que por isso seu funcionamento mental é de alguma forma diferente do dos adultos. Essa não é a perspectiva adotada pela psicanálise, pois ela compreende, de um lado, que o inconsciente é atemporal, porém entende também que há a perspectiva histórica do sujeito ligada à trajetória desenvolvida ao longo de sua vida e que possui especificidades de cada momento, como a infância. Esse será o ponto de partida discutido nesse tópico.

Freud oferece embasamento para a compreensão da premissa mencionada, diferenciando o adulto da criança colocando suas formas de expressão :

Eu não partilho a opinião, atualmente favorecida, de que o que dizem as crianças é inteiramente arbitrário e nada confiável. Não existe arbitrariedade na psique; o caráter não confiável das afirmações das crianças vem da preponderância de sua fantasia, assim como o caráter não confiável das afirmações dos adultos vem da preponderância de seus preconceitos. De resto, também a criança não mente sem motivo e, em geral, tem maior inclinação à verdade que os adultos. (FREUD, 1909, p. 105)

Pode-se entender que tudo aquilo que é expresso pelo sujeito, seja ele criança ou adulto, tem uma origem. Portanto, a criança não inventa simplesmente, e também não deixa de entender o que lhe é dito ou vivenciado, ela se expressa e compreende com as palavras que lhe estão disponíveis em seu universo de significações. Tudo aquilo que é falado tem origem nas fantasias, pois os preconceitos dos adultos também são fantasias, bem como os mecanismos utilizados para dar conta das 
angústias. Os modos à partir dos quais damos conta de viver com a nossa morte também são fantasiosos, exigem de nós um esforço constante para que não nos defrontemos com a finitude das coisas.

A real diferença que pode ser assinalada entre os adultos e as crianças está na forma como elas se expressam, ou como algumas situações serão explicadas a elas, e isso está ligado aos meios que serão utilizados para acessar a dor psíquica da criança. Neste sentido, podemos pensar no brincar da criança, por exemplo, que propicia que ela pense sobre a sua situação e fale ou demonstre o que está sentindo.

Segundo Stümer e Castro (2009), conversar com crianças e entender sobre o que se passa com elas é tarefa difícil por três motivos: no que diz respeito à interferência que elas recebem de seus familiares e terceiros por serem pequenos e ainda dependentes; o encaminhamento do pedido de ajuda, que na maioria dos casos parte dos pais e do que eles acreditam que está errado; e por fim, o fato de que a criança, ainda não utilizando as palavras no mesmo nível em que os adultos as utilizam, precisam utilizar outras formas de manifestar seus sentimentos. Desse modo:

\begin{abstract}
A psicoterapia com crianças (e em alguns casos com adolescentes) não pode ser confundida com uma psicoterapia familiar, mas, em inúmeras ocasiões, precisamos compreender a explicitar as ansiedades e o funcionamento do grupo familiar ou crenças que, muitas vezes, são transgeracionais e se atravessam na psicoterapia individual com a criança ou o jovem (CASTRO \& CIMENTI, 2000, apud STÜMER \& CASTRO 2009).
\end{abstract}

Assim, a criança utiliza uma linguagem própria, a qual não é entendida pelos adultos porque estes estão marcados pelas próprias resistências e preconceitos. Freud (1909) alega que as experiências infantis exigem uma consideração especial, pois para a análise do adulto se trabalha com aquilo que ele lembra, enquanto que nas crianças, as questões são atuais.

Dessa forma, o que é o luto, e por que temos medo do luto da criança? Freud (1917 [1915]) nos diz que, "via de regra, luto é a reação à perda de uma pessoa amada ou de uma abstração que ocupa seu lugar, como pátria, liberdade, um ideal etc.", e também nos afirma que o que diferencia o luto da melancolia, sendo a segunda um estado de "abatimento doloroso, uma cessação do interesse pelo mundo exterior, perda da capacidade de amar, inibição de toda a atividade e diminuição da autoestima [...]", é que no luto a autoestima não é afetada (FREUD, 1917 [1915], p. 249). Assim, podemos pensar que talvez o nosso medo esteja voltado para a dor da criança que será necessário enfrentar, e uma vez que a nossa própria dor muitas vezes nos 
"Viver até O Dia Da Sua Morte": Uma Discussão Acerca Dos Cuidados Paliativos Com Crianças A Partir Do Filme Operação Big Hero

traz dificuldade de enfrentamento. A dor do outro nos mostra a nossa dor. Na tentativa enérgica de contornar a constância e a certeza da morte na vida, tentamos escondêla à medida em que não falamos sobre ela, pois acreditamos que se as crianças não souberem sobre ela, não sofrerão.

De acordo com Freud (1917 [1915]), estar em luto exige do sujeito grande dispêndio de energia, e nesse processo é necessário que se entenda a perda desse objeto que recebe muito investimento libidinal, para que seja possível direcionar libido para um novo objeto. Esse processo exige tempo e pode ser muito doloroso para quem o presencia, mas isso não deve interferir na sinceridade utilizada com a criança para apresenta-Ihe a verdade dos fatos. Uma criança precisa entender o que está sentindo, realocar isso em sua vida e elaborar a sua dor.

Kovács (2016), discorre sobre o fato de negarmos essa informação aos questionamentos da infância relacionados a essa temática, colocando que essa negação também está atrelada a nossa dificuldade de falar sobre o morrer e encarar o nosso sofrimento em processo de luto ou enfretamento de uma situação que envolva a morte de alguma forma. A verdade é que negar essa informação às crianças pode evocar nelas sentimentos de medo e insegurança, bem como explicar a morte contornando os seus impactos, utilizando metáforas para isso, por exemplo, ao invés de ajudar, podem causar incompreensão e confusão.

\footnotetext{
Crianças vivem processos de luto como os adultos, necessitam de acolhimento e cuidado [...]. É um erro considerar que crianças não percebem quando ocorrem mortes e que por isso se deve agir como se nada tivesse acontecido [...]. Falar, explicar, esclarecer, não retira a dor, mas permite que a criança possa recorrer àquelas pessoas com as quais se sente mais segura [...]. (KOVÁCS, 2016, s/p).
}

Mesmo com as nossas tentativas de negar que a morte pode chegar também durante período da infância, a realidade é que as doenças graves sem possibilidade de cura também acometem crianças e podem se tornar uma parte de suas vidas. $E$, nesse sentido, sabendo que o tratamento com pacientes nessa faixa etária também acontece em ala hospitalar, e que elas perdem amigos que antes tinham muito convívio nesse ambiente e se veem em conflitos com o enfrentamento da sua morte; propomos, na análise das próximas cenas, uma compreensão dos cuidados paliativos com crianças. 


\section{Cena 03 - Falando Sobre A Descoberta da Doença E A Questão Da VERDADE}

Depois de um período descarregado, Baymax volta com Hiro para o quarto para ser ligado ao carregamento e, durante esse processo, visualiza o boné de Tadashi em cima da cama que era deste personagem. Hiro fica sensibilizado e retoma o luto pela perda do irmão. A tristeza comparece na cena representada pela música e expressões do personagem, enquanto o garoto explica para o robô que o seu irmão morreu e nunca mais voltará. Baymax alega que Tadashi estava bem e, provavelmente, ainda teria uma vida longa, Hiro diz que infelizmente houve um incêndio, um acontecimento inesperado, que mudou essa perspectiva completamente. Segue falando para Baymax que a falta de Tadashi "dói muito", mas que isso não era uma dor física, fazendo com que robô faça download de grande quantidade de estudos sobre perdas pessoais para entender o que Hiro estava passando e sentindo. A partir disso descobre que ficar perto de amigos e familiares pode auxiliar na melhora, assim como o contato físico, por isso comunica todos os amigos de Hiro. Depois disso resolve abraçá-lo, tendo em mente a importância do contato físico, e dizer que sentia muito pela morte de Tadashi.

A partir da análise desta cena, foi possível ligar à ideia de que o trabalho do cuidador paliativo é explicar o que são as mudanças sentidas pela criança durante esse processo e alguns questionamentos que podem surgir envolvendo desde a situação sentida unicamente pelo sujeito, como a reação da família ao diagnóstico apresentado. A intervenção também diz respeito à explicação do que é a doença que acometeu essa criança e como ela afeta o seu organismo, pois "crianças enfermas necessitam de explicações claras sobre o que está sendo feito no hospital, já que a internação é uma situação difícil com afastamento da família e de amigos" (KOVÁCS, 2016, s/p) e essa explicação pode ser tanto para o sujeito quanto para sua família, que também sofre com a situação. O papel do cuidador também é de extrema relevância quando se diz respeito ao exercício de escuta do paciente, sem julgamentos prévios e sem censura às angústias apresentadas. A diferença está em como será realizada a intervenção quando se pensa em adultos e crianças: para o adulto isso pode ser explicado diretamente, para a criança existem meios de esclarecer isso da melhor forma. Para que seja possível abordar esse assunto com a criança, é necessário que se leve em consideração as alternativas que são 
"Viver até O Dia Da Sua Morte": Uma Discussão Acerca Dos Cuidados Paliativos Com Crianças A Partir Do Filme Operação Big Hero

disponibilizadas para o alcance das angústias dessa fase da vida, a qual, neste caso, está imersa na situação de doença terminal, crônica ou progressiva. O modo mais utilizado para o trabalho com crianças é a brincadeira, que permite a entrada do psicólogo no universo infantil, pensando na dificuldade de expressão de sentimentos através da fala.

Segundo Melanie Klein (1997), ao brincar, a criança pode representar de maneira simbólica as ansiedades e fantasias sobre as suas experiências e, através disso, expressar os conflitos inconscientes, o que abre a possibilidade de superação de experiências que podem ser nocivas ao sujeito. Por isso é possível pensar, na utilização da brincadeira ou de outros recursos lúdicos em cuidados paliativos, como forma de ressignificação de angústias e obtenção de resultados com pacientes na fase da infância. A brincadeira, como estudado por Winnicott (1975), serve como ponte para o acesso ao inconsciente, podendo representar os sentimentos internos da criança, em que a realidade externa pode ser utilizada para mostrar o que há na realidade interna.

Podemos, assim, partir do pressuposto de que a explicação da morte para as crianças em CP pode ser feita por via da brincadeira, e a partir dai surge o entendimento de como o sujeito se sente diante de tal situação. Uma terapia que prossegue desta forma permite a aproximação dos processos inconscientes que permeiam o sujeito, viabilizando o trabalho da abertura das expressões da criança à possíveis ressignificações, o que dá contorno ao tratamento e à situação na qual esse sujeito se encontra.

Como dito anteriormente, os CP com crianças também pretendem atingir o meio familiar, pensando que o envolvimento com a família se torna indispensável nessa idade, como nos diz Castellanos (2010). Por isso as equipes multiprofissionais estão sendo ampliadas como uma estratégia de melhora e aumento na intervenção em casos de adoecimento crônico. A busca pelo aprimoramento do atendimento com a família possibilita que se ampliem os cuidados domiciliares e "manutenção do bemestar das crianças". Segundo o mesmo autor:

[...] as dinâmicas familiares produzem efeitos diversos sobre o processo de adoecimento, sobre a organização dos cuidados e sobre o próprio desenvolvimento e crescimento das crianças. Desse modo, uma linha de intensos contatos se estabelece, então, entre profissionais de saúde crianças doentes e seus familiares [...] (CASTELLANOS, 2010, p. 20). 
É a partir desse envolvimento que se torna possível estabelecer o que deve ser feito, como deve ser feito e a melhor forma de se aplicar o que foi planejado. Também é possível entender quais as expectativas que envolvem esse processo e criar afetos entre criança, equipe e familiares. Trabalhar com a família e com as instituições de saúde também nos remete à dificuldade existente nesses meios de entender as doenças crônicas, degenerativas e progressivas em crianças, devido à medicalização da infância e do cuidado direcionado a esses sujeitos, mas também nos abre a possibilidade de fazê-los entender mais sobre o processo de adoecimento e o cuidado específico nesses casos.

\section{CONSIDERAÇÕES FINAIS}

Começo as minhas considerações finais sobre o que foi trabalhado nesta pesquisa retomando o poema disposto como epígrafe. Como dito, após escolhida a temática que nos provoca sentimento de afinidade, sinto que começamos a enxergála em muitos âmbitos da nossa vida. Com esse poema tive um olhar especial devido a uma frase, a qual é "quando se morre uma cruz". Isso me remeteu aos ditados populares que são reproduzidos, e nesse caso pensei que quando falamos sobre "carregar uma cruz", nos referimos ao peso que algumas situações exercem sobre nós e que são as eventuais desventuras participantes da vida de todos os sujeitos. $O$ que quero dizer é que o sofrimento é algo inerente à existência de todos, e que sim, é pesado e exige de nós constantes ressignificações, mas ele não se faz de todo ruim. Assim como a morte, que é a única certeza que nós temos, e em contrapartida a negamos energicamente transformando essa certeza em algo deveras pesado de se carregar.

Perguntei-me muitas vezes, enquanto estudava os Cuidados Paliativos, sobre as séries de acontecimentos que nos predispõem ao enfrentamento da finidade de tudo o que nos cerca. Acabei chegando à conclusão, em diversos momentos do processo, que encarar a morte é sim uma sucessão de eventos difíceis de serem elaborados. Aos CP fica incumbida a tentativa de amenizar as angústias que transpassam esse enfrentamento da morte e da elaboração do luto encarando-as de frente.

Uma equipe de CP se encarrega, dessa forma, de auxiliar o paciente e seus familiares abdicando de um viés curativo, pois o atendimento se dá com o sujeito que está diante da sua morte, e descobre uma doença terminal, crônica, degenerativa ou

199 Psicanálise \& Barroco em revista | v.17, n. 01 | julho de 2019 
"Viver até O Dia Da Sua Morte": Uma Discussão Acerca Dos Cuidados Paliativos Com Crianças A Partir Do Filme Operação Big Hero

progressiva que já não corresponde mais a nenhum tipo de tratamento. As pessoas atendidas pela equipe multidisciplinar de CP são auxiliadas de maneira integral, sempre levando em consideração as convicções, tanto do paciente e o que eventualmente o fará sentir-se melhor, quanto da família.

Este artigo trouxe a análise do filme Operação Big Hero como arte passível de ser utilizada para compreender temáticas como morte e luto. No processo de análise das três cenas escolhidas, foi possível visualizar o filme pode ser utilizado tanto para trabalhar essas temáticas com a criança hospitalizada, propiciando reflexões e ressignificações, quanto com a criança que se depara com essa temática por um familiar hospitalizado, uma vez que os CP alcançam a família do paciente. Essa segunda hipótese de utilização do filme surge com a observação de que o personagem principal (Hiro) passa por momentos de luto, mas não necessariamente está hospitalizado.

As cenas destacadas do filme fizeram as seguintes abordagens: a discussão do início do tratamento em CP e como se dá esse tratamento, uma reflexão sobre como a criança lida com a morte e com o luto e como devemos introduzi-las nessas temáticas, a discussão da descoberta da doença e a questão da verdade sobre o tratamento e as implicações advindas do mesmo.

O enfoque da pesquisa foi o estudo do CP com as crianças, por isso apresentou as especificidades atreladas ao atendimento com essa faixa etária, que no caso estão na brincadeira, método utilizado para facilitar o acesso ao universo infantil e seus modos de ressignificar experiências. Também aborda a questão de que a maneira como abordamos as crianças privando-as da verdade acreditando que elas não conseguirão dar conta de entender grandes rupturas como a morte, por exemplo, é equivocada.

Por fim, na infância existem as expectativas que são depositadas no sujeito de pouca idade que atravessam todo o processo de elaboração da situação na qual este se insere. Em CP com crianças, então, é possível pensar na utilização de recursos lúdicos, como o filme, e outras brincadeiras que se transformem em suporte e veículo para a ressignificação das angústias. 


\section{REFERÊNCIAS}

HALL, Don; WILLIANS, Chris (Direção). Big Hero 6. Produção: Roy Conli e Kristina Reed. Produtora: Walt Disney Pictures e Marvel Entertainment. Estados Unidos, 2014. Disponível em: <https://yts.ag/movie/big-hero-6-2014> Acesso em: 23 nov. 2017.

FERREIRA, A. P. Q; LOPES, L. Q. F; MELO, M, C, B. O papel do psicólogo na equipe de cuidados paliativos junto ao paciente com câncer. Rev. SBPH. vol.14 no.2. Rio de Janeiro dez. 2011. http://pepsic.bvsalud.org/scielo.php?script=sci arttext\&pid=S1516-08582011000200007. Acesso em 30 mai. 2017.

FERREIRA, R. C; VARGA, C. R. R; SILVA, R. F. Trabalho em equipe multiprofissional: a perspectiva dos residentes médicos em saúde da família. Ciência \& Saúde Coletiva, vol.14 supl.1 Rio de Janeiro Sept./Oct. 2009. Disponível em: http://www.scielo.br/scielo.php?script=sci arttext\&pid=S1413-81232009000800015 . Acesso em: 25 mai. 2017.

FREUD, S. Análise da fobia de um garoto de cinco anos ("O Pequeno Hans", 1909). In: FREUD, S. O delírio e os sonhos na Gradiva, análise da fobia de um garoto de cinco anos e outros textos (1906-1909). Tradução de Paulo César de Souza. São Paulo: Companhia das Letras, 2015.

FREUD, S. A nossa atitude diante da morte. In: FREUD, S. Escritos sobre a Guerra e a Morte (1915). Tradução de Artur Morão. Covilhã, Portugal: Universidade da Beira Interior, 2009.

FREUD, S. Luto e Melancolia (1915). In: FREUD, S. Introdução ao narcisismo, ensaios de metapsicologia e outros textos (1914-1916). Tradução de Paulo César de Souza. São Paulo: Companhia das Letras, 2010.

GOMES, J. S. Cuidados Paliativos e Psicologia: Uma correlação na terminalidade da vida. Psicologia.pt. São Paulo - IPUSP, Brasil. 2017. Disponível em: http://www.psicologia.pt/artigos/ver_artigo.php?cuidados-paliativos-e-psicologia-umacorrelacao-na-terminalidade-da-vida\&codigo=A1116 . Acesso em: 24 de Out. 2017.

GRINFELD, P. L. P. Falando Sobre Morte com Crianças. 2016. Disponível em http://ninguemcrescesozinho.com.br/2016/06/23/falando-sobre-morte-com-criancas/. Acesso em: 26 de Out. 2017.

INCA. Cuidados Paliativos. Disponível em: https://www.inca.gov.br/tratamento/cuidadospaliativos. Acesso em: 25 mai. 2017.

KOVÁCS, M. J. Falando de Morte com Crianças. psico.usp, n.2/3, 2016. Disponível em: http://www.ip.usp.br/revistapsico.usp/index.php/30-commentor-2/79-falando-de-morte-comcriancas.html. Acesso em: 08 jun. 2017.

LIMA, N. Um olhar sobre os cuidados paliativos. Instituto da Psicanálise Lacaniana. São Paulo, 2014. Disponível em: http://www.ipla.com.br/editorias/saude/um-olhar-sobre-oscuidados-paliativos.html. Acesso em: 08 Jun. 2017.

MELO, P. O; SILVA A. M. C.A Psicanálise de Crianças: o Brincar como Recurso Terapêutico. PSICOLOGADO Artigos, Cidade Nova, Montes Claros, 2012. Disponível em: https://psicologado.com/abordagens/psicanalise/a-psicanalise-de-criancas-o-brincar-comorecurso-terapeutico . Acesso em: 8 Jun. 2017. 
SANTOS, F. Cuidados Paliativos e Síndrome de Burnout: um olhar profilático. In SANTOSD, F. Cuidados Paliativos: Diretrizes, Humanização e Alívio de Sintomas. São Paulo, Atheneu, 2011.

SILVA, E. P. SUDIGURSKI, D. Concepções Sobre Cuidados Palitivos: Revisão Bibliográfica. Acta paul. enferm. vol.21 no.3 São Paulo 2008. Disponível em: http://www.scielo.br/scielo.php?script=sci_arttext\&pid=S0103-

21002008000300020\&lng=en\&nrm=iso\&tlng=pt . Acesso em: 24 Out. 2017.

VICENSI, M, C. Reflexão sobre a morte e o morrer na UTI: a perspectiva do profissional. Rev. Bioét. vol.24 no.1. Brasília. Jan./Apr. 16. Disponível em: http://www.scielo.br/scielo.php?script=sci arttext\&pid=S1983-80422016000100064 Acesso em: 07. nov. 2016. 


\title{
“Live Till The Day Of DeAth”: A Discussion On Palliative On Children With Reference To The Film Big Hero
}

\begin{abstract}
Palliative care consists of the multidisciplinary focus on seriously ill people, with a great risk of death. In the case of children, their special needs should be attended to and means for the access of children imaginary should be constructed. Current essay deals with the application of palliative care in children and comprises the use and analysis of Big Hero, a cartoon film. Three scenes were chosen which gave rise to three aspects of palliative care processes: the start of treatment and how it occurs; the manner children deal with death and bereavement; the issue of telling the truth on treatment and its implications. Results show the relevance of the family in the treatment and the film strategy as facilitator of children's access to the theme.
\end{abstract}

KEYWORDS: Paliative Care, Death, Grief, Children, Film, Psychoanalysys. 


\section{“VIVRE JUSQU'AU JOUR DE SA MORT”: UNE Discussion À Propos De Soins Palliatifs Sur Des Enfants Basée Sur Le Filme Operation Big Hero}

\section{RÉSUMÉ}

Les soins palliatifs sont compris comme l'attention dispensée aux soins multidisciplinaires accordés aux personnes en grave état de santé et risque effectif de mort. Les soins palliatifs aux enfants doivent respecter leurs caractéristiques tout en construisant des moyens pour accéder à l'univers enfantin. Cet article a pour but de faire comprendre comment les soins palliatifs sont dispensés aux enfants et cela à travers une analyse du filme d'animation « Opération BIG HERO ». Trois scènes ont été choisies à partir desquelles il a été possible d'analyser trois aspects des soins palliatifs : le début du traitements et comment il se déroule, la façon dont les enfants font face à la mort et au deuil, plus encore la vérité à propos du traitement et ses implications. II ressort de cette étude que la famille est importante durant le traitement des enfants, en outre les filmes sont une stratégie facilitatrice d'accès à cette thématique.

MOTS-CLÉS : Soins Palliatifs, Mort, deuil, Enfant, Film, Psychanalyse. 
Recebido em: 16-04-2019

Aprovado em: 02-06-2019

(C) 2019 Psicanálise \& Barroco em revista

http://www.seer.unirio.br/index.php/psicanalise-barroco/index

revista@psicanaliseebarroco.pro.br

Programa de Pós-Graduação em Memória Social — UNIRIO.

Memória, Subjetividade e Criação.

http://www.memoriasocial.pro.br/proposta-area.php

205 Psicanálise \& Barroco em revista | v.17, n. 01 | julho de 2019 